\title{
ANTYKOLIZYJNY SYSTEM RADAROWY I JEGO WSPÓŁPRACA Z POKŁADOWYMI SYSTEMAMI AUTOMATYCZNEGO STEROWANIA
}

\begin{abstract}
Wzrastające wymagania dotyczące poprawy bezpieczeństwa w ruchu obiektów latających pilotowanych i bezzałogowych stało się impulsem do podjęcia w ramach konsorcjum kierowanego przez Instytut Lotnictwa próby skonstruowania systemu antykolizyjnego. Celem przedsięwzięcia było skonstruowanie autonomicznego systemu do wykrywania nieruchomych i ruchomych przeszkód oraz określanie odległości od nich i prędkości, z jaką się poruszają. Zastosowanie w systemie radarowego detektora przeszkód pozwala na skuteczne jego wykorzystanie przy braku widzialności w nocy oraz we mgle lub zapyleniu. System posiada rozszerzony zakres działania umożliwiający wykonywanie cyfrowego pomiaru względnej wysokości lotu i prędkości pionowej, stanowiących podstawę do wykrycia zagrożenia zderzenia z podłożem. Przygotowano elementy oprogramowania, które w przyszłości zapewnią współpracę systemu antykolizyjnego z innymi systemami automatycznego sterowania lotem. Opracowany projekt systemu był podstawą do zbudowania pierwszego próbnego egzemplarza. Przeprowadzono na nim wstępne badania laboratoryjne i pierwsze testy w locie. W pracy opisano sposób współdziałania poszczególnych urządzeń oraz zakres wykonywanych przez nie funkcji.
\end{abstract}

Słowa kluczowe: systemy sterowania, systemy radarowe, system antykolizyjny, detektor przeszkód

\section{Cel i zadania systemu antykolizyjnego}

Głównym celem systemu antykolizyjnego jest wykrycie przeszkody, pomiar jej odległości od obiektu oraz określenie jej prędkości. Istotną jego funkcją jest sprawdzenie, czy istnieje zagrożenie wystąpienia kolizji z wykrytą przeszkodą [1,2]. Ważnym zadaniem jest pomiar oraz wyliczenie niezbędnych danych koniecznych do wyboru i wykonania manewru antykolizyjnego i manewru omijania [3]. Zagadnienie dotyczące manewru antykolizyjnego jest znacznie złożone ze względu na istnienie bardzo dużej liczby możliwych różnych sytuacji i konfiguracji występowania przeszkód ruchomych i nieruchomych, ich wielkości i sposobu rozmieszczenia. Sam system antykolizyjny jest przygotowany do

\footnotetext{
${ }^{1}$ Autor do korespondencji/corresponding author: Jerzy Graffstein, Instytut Lotnictwa, al. Krakowska 110/114, 02-256 Warszawa, tel.: (22) 8460011, ext. 271, e-mail: jgraff@ilot.edu.pl
} 
wykrywania nieruchomych i ruchomych przeszkód. Wystąpienie zagrożenia $\mathrm{z}$ nieprzewidzianą $\mathrm{i}$ wcześniej nieznaną przeszkodą $\mathrm{w}$ zależności od sytuacji powoduje konieczność podjęcia jednego z dwóch rodzajów działań: wykonania antykolizyjnego manewru i powrót do lotu wzdłuż zaplanowanej trasy lub zmiana planu trasy w celu uniknięcia kolizji. Druga z wymienionych możliwości wymaga wykrycia przeszkody w dostatecznej odległości, a co się z tym wiąże - istnienia dostatecznej ilości czasu potrzebnego na podjęcie odpowiednich działań związanych z rekonfiguracją planu lotu. Drugim istotnym warunkiem wykonania takiej rekonfiguracji jest posiadanie przed jej rozpoczęciem kompletnej informacji o wykrytej przeszkodzie. Najczęściej występują przeszkody nieprzewidziane, na temat których system nie posiada kompletnych informacji. Radarowy detektor w trakcie lotu obiektu ,widzi” początkowo przeszkodę tylko od jednej strony, pozostałe części przeszkody nie są widoczne. W związku z tym w pracy nie jest rozważany sposób postępowania dla rekonfiguracji planu lotu, a jako dopuszczalny przyjęto scenariusz powrotu do lotu wzdłuż zaplanowanej trasy (ewentualnie lotu do celu). Pojawienie się przeszkody i wystąpienie zagrożenia kolizji wymaga wykonania wielu działan realizowanych w ramach dwóch podstawowych faz lotu:

- manewru antykolizyjnego,

- powrotu do lotu wzdłuż zaplanowanej trasy lub najkrótszą drogą do celu.

Manewr uniknięcia kolizji jest takim ruchem obiektu latającego, który ma ten obiekt doprowadzić do punktu (i takich parametrów lotu), w którym nie będzie występowało niebezpieczeństwo zderzenia z przeszkodą. Ruch omijania przeszkody odbywa się w niedużej, ale bezpiecznej odległości od przeszkody, uwzględniającej zachowanie odpowiedniego marginesu bezpieczeństwa [4]. Powrót do lotu wzdłuż trajektorii zgodnej z planem lotu jest wykonywany po zakończeniu omijania przeszkody. Wykonanie bezpiecznego autonomicznego lotu wymaga, aby system antykolizyjny ściśle współpracował z innymi pokładowymi systemami lotniczymi (rys. 1.). W dalszej części rozdziału zostanie opisana propozycja współdziałania systemu antykolizyjnego z pokładowymi systemami autonomicznego lotu.

Po uzyskaniu informacji o zagrożeniu możliwością wystąpienia kolizji system zarządzania manewrem antykolizyjnym uruchamia procedurę wyszukiwania odpowiedniego manewru antykolizyjnego. W systemie antykolizyjnym jest wyliczany czas, w którym najpóźniej musi zostać uruchomiony manewr antykolizyjny. System zarządzania lotem podejmuje decyzję o przerwaniu wykonywania planu lotu i o uruchomieniu wybranego przez system antykolizyjny odpowiedniego manewru. Wszystkie informacje niezbędne do podjęcia tej decyzji są dostarczane przez system antykolizyjny. Kontrola nad wykonaniem zadania uniknięcia zderzenia z przeszkodą jest przekazywana przez system zarządzania lotem do systemu zarządzania manewrem antykolizyjnym. Dane o wybranym manewrze antykolizyjnym są przekazywane do systemu zarządzania powrotem na trasę. 


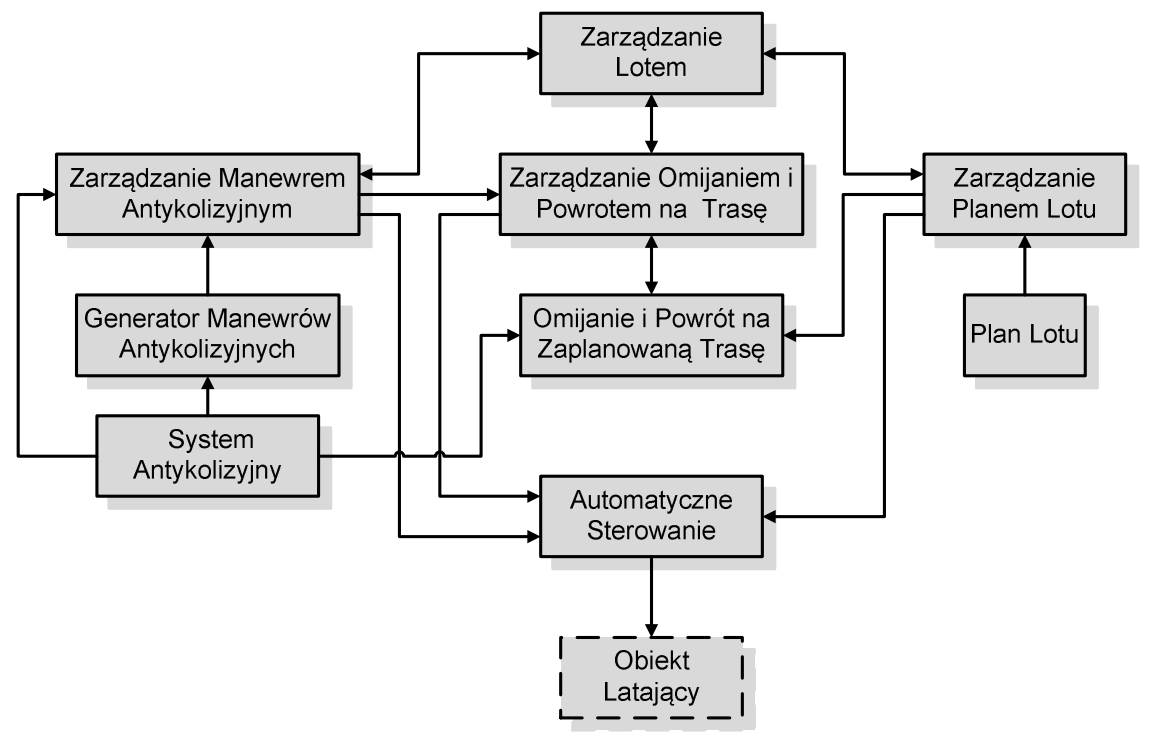

Rys. 1. Współpraca systemu antykolizyjnego z systemami automatycznego sterowania lotem

Fig. 1. Cooperation of anti-collision systems with systems of the automatic flight control

Przed zakończeniem wykonania antykolizyjnego manewru są wyliczane wartości zadane, wymagane do rozpoczęcia wykonania fazy omijania przeszkody i powrotu na trasę. Informacja o wykonaniu manewru antykolizyjnego jest przekazywana do systemu zarządzania lotem, który przekazuje kontrolę do systemu zarządzania powrotem na trasę. Na tym etapie przebieg lotu jest podyktowany wymogami wynikającymi $\mathrm{z}$ przyjętego sposobu omijania przeszkody. $\mathrm{W}$ tej części lotu są wykorzystywane informacje z systemu antykolizyjnego dostarczającego uzupełniające dane o omijanej przeszkodzie. Ominięcie przeszkody o małych wymiarach ( $w$ porównaniu $\mathrm{z}$ obiektem lub odległością, z której rozpoczęto manewr) może zostać wykonane w trakcie manewru antykolizyjnego. Sposób powrotu do lotu po zaplanowanej trasie odbywa się zgodnie z przyjętymi kryteriami, np. najkrótsza droga powrotu, najkrótszy czas powrotu. Fakt doprowadzenia obiektu na odpowiednio małą odległość od planowanej trasy jest sygnalizowany przez system zarządzania powrotem i przekazywany do systemu zarządzania lotem. Ten ostatni przekazuje kontrolę do systemu zarządzania planem lotu i od tego momentu rozpoczyna się kontynuacja wykonania pozostałej części planu lotu. W wyjątkowych sytuacjach konieczne może się okazać cofnięcie wzdłuż zaplanowanej trajektorii do wcześniejszego wybranego punktu leżącego na niej. Wykonanie powrotu może być uwarunkowane wymogami realizacji zaplanowanej misji na wcześniejszym odcinku zaplanowanej trasy. W tym celu należy sprawdzić, czy powrót taki jest możliwy z punktu wi- 
dzenia bezpieczeństwa lotu, z uwzględnieniem istniejącej przeszkody, która wcześniej zakłóciła lot obiektu. W takiej sytuacji ma się do czynienia z przypadkiem pewnej formy rekonfiguracji planu lotu.

\section{Struktura systemu antykolizyjnego}

Na schemacie przedstawiono ogólną ideę systemu antykolizyjnego AURA. W jego skład wchodzą następujące elementy (rys. 2.):

- radarowy detektor przeszkód (RDP),

- cyfrowy radiowysokościomierz (CRW),

- mikrokomputer AXMOD RDP,

- mikrokomputer AXMOD CRW,

- centralny komputer systemu antykolizyjnego,

- mapa terenu i baza przeszkód,

- system odniesienia AHRS.

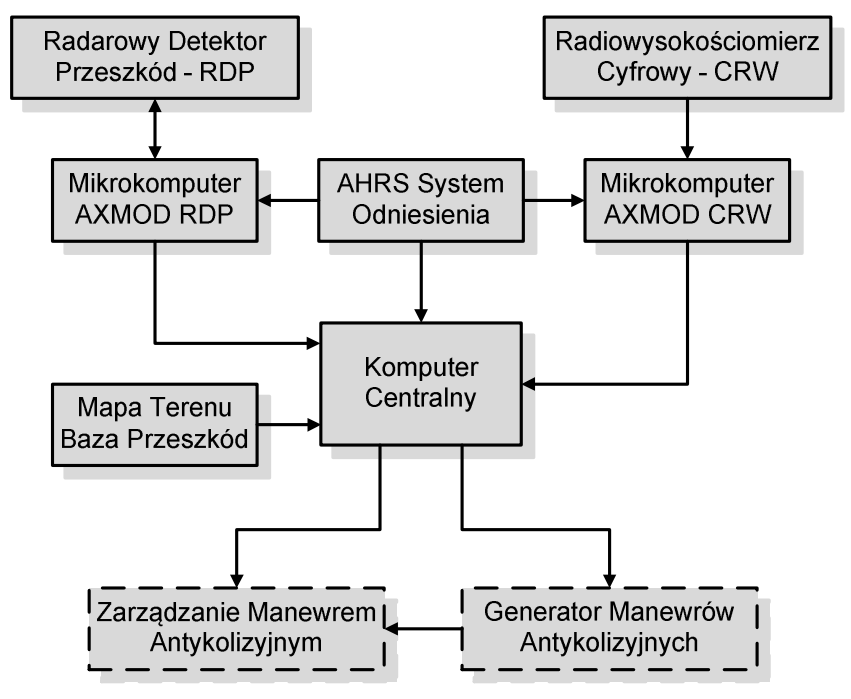

Rys. 2. Struktura systemu antykolizyjnego

Fig. The structure of anti-collision system

System jest autonomiczny i wykorzystuje trzy źródła informacji o przeszkodach: radarowy detektor przeszkód, cyfrowy radiowysokościomierz oraz mapę terenu z bazą przeszkód. RDP wykrywa przeszkody ruchome i nieruchome oraz określa ich odległość od obiektu, a dla ruchomych przeszkód wylicza ich prędkości przemieszczania. CRW wykonuje pomiary wysokości lotu obiektu względem powierzchni Ziemi oraz prędkość zmian tej wysokości. Przetwarzanie pierwotnego sygnału uzyskanego z RDP i CRW na odpowiednie wielkości fi- 
zyczne jest dokonywane w mikrokomputerze AXMOD RDP i AXMOD CRW. Baza przeszkód jest zbiorem informacji dotyczących statycznych naziemnych przeszkód na obszarze obejmującym zadaną trajektorię lotu. Zawiera także dane dotyczące wysokości powierzchni terenu. Komputer centralny jest przewidziany do zbierania przetworzonych informacji z urządzeń pomiarowych i zaimplementowania programu tworzącego model otoczenia [3] oraz interfejsu z systemami automatycznego sterowania. Jego zadaniem jest, na podstawie informacji otrzymanych z RDP i danych o ruchu latającego obiektu uzyskanych z AHRS i CRW, stworzenie zaktualizowanej bazy przeszkód zawierającej odpowiednie ich reprezentacje w przestrzeni. W każdym kroku, w którym następuje odczyt nowych danych z posiadanych źródeł informacji, jest dokonywane sprawdzenie, czy zaistniało niebezpieczeństwo kolizji z wykrytą przeszkodą [2]. Spełnienie tego warunku powoduje przesłanie sygnału do systemu zarządzania lotem.

\section{Urządzenia sytemu antykolizyjnego}

Radarowy detektor przeszkód jest podstawowym urządzeniem, które dostarcza do systemu antykolizyjnego informację o aktualnej sytuacji w przestrzeni otaczającej latający obiekt. Składa się z dwóch modułów nadawczo-odbiorczych pracujących z częstotliwością $24 \mathrm{GHz}$. Każdy z nich jest umieszczony razem $\mathrm{z}$ antenami nadawczą i odbiorczą na jednej płytce elektronicznej, zamocowanymi w górnej części sztywnej, obrotowej platformy po dwóch przeciwnych jej stronach (rys. 3.). Sygnał jest zbierany na przemian z jednego i drugiego modułu $\mathrm{i}$ jest formowany $\mathrm{w}$ modulatorze, a następnie $\mathrm{w}$ filtrze dolnoprzepustowym oraz wzmacniaczu. Tak przetworzony sygnał z części ruchomej jest przekazywany poprzez wielokanałowe złącze obrotowe (wyposażone w pierścienie ślizgowe) do 16-bitowego przetwornika analogowo-cyfrowego znajdującego się w dolnej, nieruchomej części obudowy RDP. Cyfrowy sygnał podlega numerycznej obróbce w mikrokomputerze AXMOD-RDP. Wykonywana jest tam m.in. szybka transformata Fouriera. Na podstawie wyników analizy uzyskanego widma sygnału stwierdza się, czy w danym sektorze wystąpiła przeszkoda. Po jej wykryciu są określane dwa istotne, charakterystyczne parametry: odległość pomiędzy obiektem a przeszkodą oraz prędkość radialna względem obiektu latającego. RDP ma możliwość wykrycia do pięciu przeszkód w jednym sektorze i przyporządkowania im wymienionych, charakterystycznych parametrów. Detekcja jest realizowana w płaszczyźnie horyzontalnej w części przedniej półsfery, mieszczącej się w wycinku koła o wartości $156^{\circ}$ symetrycznie usytuowanym względem podłużnej osi obiektu. Odpowiada to 13 sektorom o szerokości po $12^{\circ}$ każdy. Prędkość kątowa platformy jest utrzymywana na stałym poziomie ok. $19 \mathrm{rad} / \mathrm{s}$. Do pomiaru prędkości kątowej w układzie stabilizacji jest wykorzystywany czujnik halotronowy. Zasięg działania detektora wynosi około $200 \mathrm{~m}$. Zależy on od wielkości powierzchni przeszkody i kształtu oraz rodzaju materiału, z którego jest zrobiona. Obudowa RDP (rys. 3.) ma kształt walca, którego 
maksymalna średnica wynosi $170 \mathrm{~mm}$, a wysokość $150 \mathrm{~mm}$. Całkowita masa urządzenia $\mathrm{z}$ obudową i umieszczonym $\mathrm{w}$ jej wnętrzu mikrokomputerem AXMOD-RDP nie przekracza $1,9 \mathrm{~kg}$.
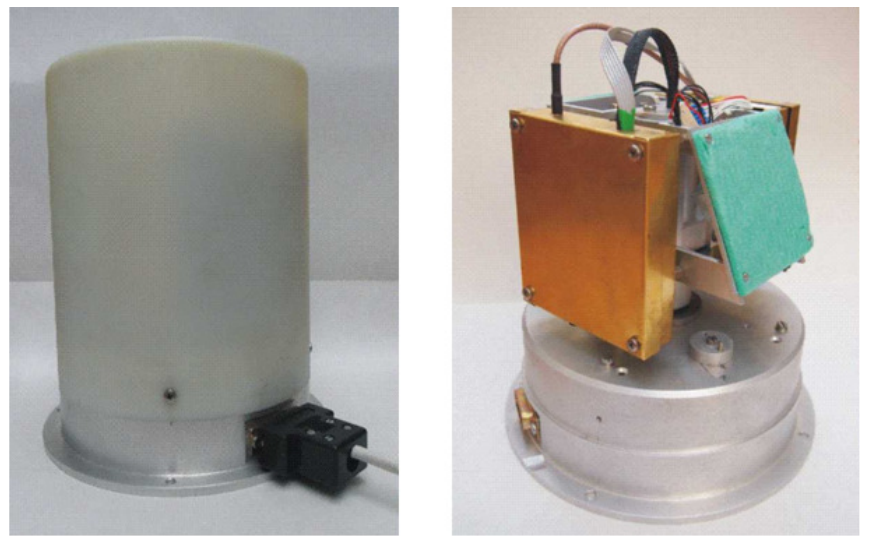

Rys. 3. Radarowy detektor przeszkód (RDP)

Fig. 3. Radar-based Obstacles Detector (ROD)

Układ odniesienia (Attitude and Heading Reference System - AHRS) typu IG-500N (rys. 4.), oferowany przez firmę SBG Systems [5], wykonuje pomiary położenia kątowego i liniowego obiektu latającego w przestrzeni, a także dostarcza trzy składowe jego prędkości liniowej i kątowej oraz składowe przyśpieszenia. Maksymalna częstotliwość próbkowania systemu AHRS wynosi $100 \mathrm{~Hz}$. Wbudowany układ GPS wylicza położenie we współrzędnych geograficznych z częstotliwością $4 \mathrm{~Hz}$ [5] oraz wysokość bezwzględną korygowaną od czujnika ciśnieniowego. Uzyskane informacje z systemu AHRS o położeniu kątowym i liniowym oraz prędkości obiektu latającego służą do wyliczenia bezwzględnego położenia i prędkości wykrytej przeszkody. Przykładowo, dokładności statycznych pomiarów kątów położenia obiektu uzyskiwane z AHRS mieszczą
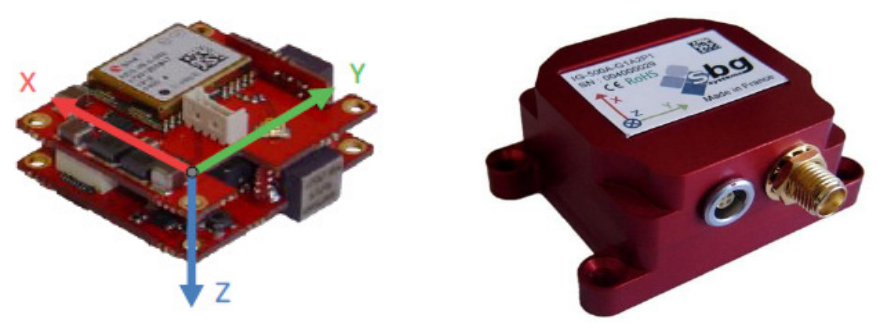

Rys. 4. System AHRS IG-500N SBG

Fig. 4. The AHRS IG-500N SBG system 
się $\mathrm{w}$ granicach $\pm 1^{\circ}$. Osiągane dokładności pomiarów klasyfikują system w średniej klasie tego typu przyrządów. Zaletą omawianego urządzenia są jego małe wymiary 36 × 49 × $22 \mathrm{~mm}$ i bardzo mała masa $46 \mathrm{~g}$ (bez anteny GPS).

Cyfrowy radiowysokościomierz (CRW), zaprojektowany i wykonany w Instytucie Lotnictwa, dokonuje pomiarów wysokości obiektu latającego względem powierzchni Ziemi od 0 do $300 \mathrm{~m} \mathrm{z}$ częstotliwością $20 \mathrm{~Hz}$. Uzyskiwana dokładność wynosi $\pm 1 \mathrm{~m}$ w zakresie od 0 do $20 \mathrm{~m}$, a powyżej tego zakresu nie jest gorsza niż ok. $\pm 5 \%$. Prędkość pionowa jest mierzona od \pm 1 do $\pm 30 \mathrm{~m} / \mathrm{s}$. CRW jest bardziej wiarygodnym źródłem informacji o wysokości względnej w porównaniu z AHRS. Z tego powodu CRW pełni istotną rolę, szczególnie w sytuacji, gdy nie jest możliwe korzystanie z bazy danych dotyczących wysokości terenu. Korelacja wysokości względnej i tendencji jej zmian może umożliwić prognozowanie niebezpieczeństwa zderzenia latającego obiektu z powierzchnią terenu. Urządzenia $\mathrm{z}$ systemem anten i mikrokomputer AXMOD-CRW są umieszczone w obudowie o wymiarach 204 x 91 x $55 \mathrm{~mm}$, a jego całkowita masa nie przekracza $1,1 \mathrm{~kg}$. Baza danych ukształtowania terenu składa się z plików tekstowych (oferowanych np. przez firmę Geosystem), zawierających informację o wysokości terenu z uwzględnieniem obiektów znajdujących się na powierzchni Ziemi. Dane zostały przygotowane przez wspomnianą firmę w prostokątnym układzie współrzędnych z rozdzielczością 20 x $20 \mathrm{~m}$.

\section{Wnioski}

System po odpowiednim dostosowaniu (głównie w zakresie oprogramowania) może być wykorzystany w obiektach bezzałogowych $\mathrm{z}$ automatycznie sterowanym lotem lub sterowanych zdalnie, a także w obiektach załogowych z pilotem. Zastosowanie opisanego systemu antykolizyjnego do lotów autonomicznych wymaga $\mathrm{z}$ jednej strony opracowania rozbudowanego systemu automatyzacji lotu, z drugiej wykonania złożonego oprogramowania, które pozwoli na ścisłą współpracę systemu antykolizyjnego z systemami automatyzacji lotu. $\mathrm{W}$ przedstawionym materiale zawarto istotne wskazania dotyczące sposobu zapewnienia odpowiedniej, programowej współpracy pomiędzy wymienionymi systemami. Osobnym zagadnieniem jest sposób przejmowania kontroli lotu pomiędzy systemem antykolizyjnym a modułem realizującym automatyczny lot wzdłuż zadanej trajektorii lotu. Opisany system ze względu na zasięg RDP może znaleźć zastosowanie na obiektach poruszających się z prędkością nie większą niż $50 \mathrm{~m} / \mathrm{s}$. Dokładniejsza granica tej prędkości jest możliwa do określenia po uzyskaniu informacji o charakterystykach manewrowych wybranego obiektu. System był poddany wstępnym badaniom podczas lotu na dwuosobowym śmigłowcu A600 Talon. Uzyskane wyniki świadczą o konieczności przeprowadzenia dalszych badań w celu precyzyjnego sprawdzenia założonych parametrów i wprowadzenia ewentualnych modyfikacji. Udoskonalanie algorytmów obróbki 
sygnałów pomiarowych pozwoli na zwiększenie odporności systemu na zakłócenia i skuteczniejszą wykrywalność przeszkód.

\title{
Literatura
}

[1] Graffstein J.: Dobór parametrów manewru antykolizyjnego i jego przebieg. Prace Instytutu Lotnictwa w Warszawie, 224 (2012), 32-45.

[2] Graffstein J.: Elementy procesu wykrycia zagrożenia kolizją i automatycznie sterowany manewr awaryjny. Pomiary Automatyka Robotyka, 2 (2012), 383-387.

[3] Jankowski S., Szymański Z., Szczyrek J., Graffstein J.: Metoda tworzenia modelu otoczenia z pomiarów radarowego detektora przeszkód w systemie unikania kolizji. Prace Instytutu Lotnictwa w Warszawie, 224 (2012), 20-31.

[4] Graffstein J.: Metoda automatycznego sterowania ruchem samolotu wykonującym manewr antykolizyjny. Zeszyty Naukowe Akademia Marynarki Wojennej w Gdynii, 185A (2011), 179-188.

[5] IG-500N GPS aided AHRS User Manual. SBG Systems, 2009.

\section{ANTI-COLLISION RADAR-BASED SYSTEM AND ITS COOPERATION WITH ON-BOARD AUTOMATIC CONTROL SYSTEMS}

\begin{abstract}
Growing requirements for an air traffic safety of pilot and pilotless aircraft were the impulse to carry on the design of anti-collision system in the Institute of Aviation. The aim of the project was the design of the autonomous system capable to detect both moving and static obstacles as well as to estimate the distance between the aircraft and obstacles and their relative velocity. Application of radar-based obstacle detector in the system allows for effective its using in the novisibility conditions at night and in the fog or dustiness. The system has extend scope of activity capable to take digital measure of relative flight altitude and vertical velocity which parameters decided about detection of collision hazard of falling to earth. The software elements that in the future will provide cooperation of anti-collision system with other automatic systems of flight control have been prepared. Based on the developed project of the system the test prototype has been built. The preliminary laboratory testing and flight tests of the prototype system have been performed. In the paper the method of cooperation of particular devices and the scope of their functions have been described.
\end{abstract}

Keywords: control systems, radar-based systems, anti-collision system, obstacles detector

DOI:10.7862/rm.2013.24

Otrzymano/received: 15.09 .2013

Zaakceptowano/accepted: 22.10.2013 